\title{
O DIREITO À EDUCAÇÃO AO LONGO DA VIDA NO ART. 25 DO ESTATUTO DO IDOSO
}

\section{THE CONCEPT OF "LIFELONG EDUCATION" (LE) INCLUDED IN THE ARTICLE 25 OF № 10.741 STATUTE}

\author{
ANA PAULA BARBOSA-FOHRMANN ${ }^{1}$ \\ LUANA ADRIANO ARAÚJO ${ }^{2}$
}

RESUMO: Investiga-se, neste trabalho, o conceito de "Educação ao Longo da Vida" (ELV) incluído na redação do art. 25 da Lei № 10.741, de $1^{\circ}$ de outubro de 2003 (Estatuto do Idoso). Aborda-se, inicialmente, o histórico normativo do direito à educação de pessoas idosas no contexto nacional, para se perscrutar, em seguida, o conteúdo da Lei №. 8.842, de 4 de janeiro 1994 (Política Nacional do Idoso) e do Estatuto do Idoso no âmbito da temática em análise. Em seguida, abordam-se o significado e o alcance do conceito de "Educação ao Longo da Vida" para se compreender o âmbito de interseção e/ou divergência entre esta concepção e as de "Educação Permanente" (EPE) e “Aprendizagem ao Longo da Vida" (ALV), apontando o referencial interpretativo pertinente ao viés da Educação ao Longo da Vida na Perspectiva da Educação Popular. Por fim, analisa-se o direito à educação ao longo da vida na perspectiva recentemente inserida no Estatuto do Idoso, considerando o processo legislativo a partir do qual se reconheceu, como princípio básico do ensino, a garantia do direito à educação e à aprendizagem ao longo da vida.

Palavras-Chave: Direito à Educação; Direito dos Idosos; Educação ao Longo da Vida.

${ }_{1}$ Professora Adjunta da Faculdade Nacional de Direito da Universidade Federal do Rio de Janeiro (FND/UFRJ). Professora Permanente do Programa de Pós-Graduação em Direito da UFRJ. PósDoutora e Doutora pela Ruprecht-Karls Universität Heidelberg. E-mail: apaula_cb@hotmail.com.

2 Mestre em Direito Constitucional pela Universidade Federal do Ceará (FD/UFC). Coordenadora do Árvore-ser (Grupo de Estudos Aplicados em Direitos das Pessoas com Deficiência). E-mail: luana.adriano88@gmail.com. 
ABSTRACT: This paper examines the concept of "Lifelong Education" (LE) included in the article 25 of Law № 10.741, of October 1st, 2003 (Statute of the Elderly). It approaches the normative history of the right to education of the elderly in the national context, in order to examine the content of Law No. 8.842, of January 4th, 1994 (National Policy for the Elderly) and of the Statute of the Elderly in the context of the subject under analysis. Furthermore, the meaning and the scope of the concept of "Lifelong Learning" (ELV) are discussed in order to understand the scope of intersection and/or divergence between this concept and the notions of "Permanent Education" (PE) and "Lifelong Learning" (LL). This article also points out the interpretative referential pertinent to the bias of Lifelong Education in Popular Education's Perspective. Finally, the right to lifelong education is analyzed in the perspective recently inscribed in the Statute of the Elderly, considering the legislative process which recognized the right to education and lifelong learning as a basic principle of education the guarantee of the right to education and of lifelong learning was recognized as a basic principle of education.

KEYWORDS: Right to Education; Rights of Older Persons; Lifelong Education.

\section{INTRODUÇÃO}

O direito à educação, além de compor o rol de direitos sociais, condiciona a garantia de efetivação dos demais direitos civis, políticos, econômicos, sociais e culturais, evidenciando a interdependência e a indivisibilidade afeta aos direitos humanos (MARTIN et al., 2015, p. 56). Tomasevski aponta que o acesso à educação funciona como um multiplicador, dado que sua configuração influencia no gozo de todos os direitos e liberdades individuais, qualificando-se sua negação ou violação como um potencial óbice ao gozo de prerrogativas fundamentais (TOMASEVSKI, 2001, p. 10). Por outro lado, em virtude da noção de que o serviço educacional deve ser fornecido, prioritária ou exclusivamente, às gerações mais jovens, as pessoas idosas findam por experimentar limitações quanto ao exercício desta prerrogativa, e isso implica um aprofundamento das possíveis infrações de direitos humanos que venham a sofrer.

De acordo com o Plano de Ação Internacional de Madrid para o envelhecimento, elaborado em 2002, a educação é uma base crucial para uma vida ativa, aportando, ademais, que a educação ao longo da vida e a formação permanente são pré-requisitos para a participação social e laboral, influenciando no gozo da saúde e do bem-estar por pessoas idosas (UNITED NATIONS, 2002). A educação ao longo da vida, conforme consignado na Declaração de Hamburgo, implica "repensar o conteúdo que reflita certos fatores como idade, igualdade entre os sexos, necessidades especiais, idioma, cultura e disparidades econômicas" (UNESCO, 1997). 
Considerando-se a perspectiva de educação ao longo da vida, modificou-se, por meio da Lei $\mathrm{n}^{\mathrm{o}}$ 13.535, de 15 de dezembro de 2017, a redação do art. 25 da Lei № 10.741 , de $1^{\circ}$ de outubro de 2003 (Estatuto do Idoso), acolhendo referido conceito no âmbito da efetivação dos direitos das pessoas idosas. Objetiva-se, nesta investigação, compreender referida reorientação conceitual, desvelando os impactos da educação ao longo da vida na formulação à educação de pessoas idosas. Traça-se, inicialmente, o histórico normativo desta prerrogativa no contexto nacional, fixando como marco inicial a Constituição Federal de 1988 para se investigar, em seguida, o conteúdo da Lei №. 8.842, de 4 de janeiro 1994 (Política Nacional do Idoso) e do Estatuto do Idoso na temática enfocada. Em um segundo momento, averiguam-se o significado e o alcance do conceito de "Educação ao Longo da Vida" (ELV) para se compreender o âmbito de interseção e/ou divergência entre esta concepção e as de "Educação Permanente" (EPE) e "Aprendizagem ao Longo da Vida" (ALV).

Desvela-se, ainda, o enquadramento da Educação ao Longo da Vida dentro do âmbito da educação formal ou não-formal. Destaca-se, por fim, o referencial interpretativo da Educação ao Longo da Vida na Perspectiva da Educação Popular (GADOTTI, 2016, p. 64; PONTUAL, 2016, p. 70). Ao final, investiga-se o direito à educação ao longo da vida na perspectiva recentemente inserida no Estatuto do Idoso, analisando, de início, o processo legislativo de promulgação deste texto, bem como a modificação da Lei № 9.394 de 20 de dezembro de 1996 (LDBEN) pela Lei № 13.632 de 6 de março de 2018, que acolhe o direito à educação e à aprendizagem ao longo da vida como princípio básico do ensino.

\section{HISTÓRICO BRASILEIRO DO DIREITO À EDUCAÇÃO DE PESSOAS IDOSAS}

Um serviço educacional voltado especificamente para o idoso nem sempre foi alvo de políticas educacionais brasileiras. Destarte, nem sempre foram consideradas as peculiaridades educacionais atinentes à faixa etária específica da pessoa idosa, tradicionalmente enquadradas, nos documentos oficiais, como pertinentes ao estado de adulto. Nesse sentido, Oliveira afirma que os sistemas educacionais vêm, historicamente, centralizando um olhar essencialista voltado para a criança em detrimento dos jovens e adultos, na medida em que a infância é vista como o tempo de aprendizagem e fase de desenvolvimento psicossocial da criança, enquanto o adulto é considerado pronto em seu processo de formação (OLIVEIRA, 2009, p. 14). Em virtude disto, ressalta Gadotti que é preciso "respeitar o educando adulto, utilizando-se uma metodologia apropriada, que resgate a importância de sua biografia, da sua história de vida" e não a sua humilhação "por uma metodologia que lhes nega o direito de afirmação de sua identidade, de seu saber, de sua cultura" (GADOTTI, 2014, p. 17).

Para compreender os marcos legislativos que fundamentam o direito à educação de idoso, trata-se, nesta seção, do art. 205 da CF/88, que estabelece a educação como 
um direito de todos e dever do Estado e da família, a ser promovida e incentivada com a colaboração da sociedade, visando ao pleno desenvolvimento da pessoa, seu preparo para o exercício da cidadania e sua qualificação para o trabalho. Coteja-se o art. 205 com o conteúdo dos arts. 227 e 230 da Lei Maior para se analisar o dever de asseguração prioritária do direito à educação para crianças, adolescentes e jovens adultos, derivado do primeiro preceptivo, em contraste com o dever de amparo às pessoas idosas. Em seguida, averígua-se o conceito de "Universidade aberta para a terceira idade", pertinente ao art. 10, inc. III, alínea " $\mathrm{f}$ " da Política Nacional do Idoso, compreendido, neste diploma, como "meio de universalizar o acesso às diferentes formas do saber". Por fim, analisa-se a instituição explícita e direta, constante no Estatuto do Idoso de 2003, do dever de incumbência da família, da comunidade, da sociedade e do Poder Público de assegurar com absoluta prioridade a efetivação do direito à educação.

\section{Constituição Federal de 1988: para as crianças, a educação; para os idosos, o amparo?}

A Constituição Federal de 1988 consagra um tratamento nunca antes dado aos direitos fundamentais, sendo resultado de um amplo processo de discussão ensejado pela redemocratização do País após mais de duas décadas de ditadura. De acordo com Sarlet, o Texto Constitucional apresenta, notadamente, três características consensualmente atribuídas, qualificando-se, portanto, como extensiva (qualidade expressa na quantidade de dispositivos normativos, uma vez que possui 246 artigos e 74 disposições transitórias), pluralista (característica advinda da consideração de reivindicações nem sempre afinadas entre si, gerando um texto com tensões internas) e de cunho programático ou dirigente (caráter consubstanciado na quantidade de disposições dependentes de regulamentações posteriores) (SARLET, 2006, p. 77-78). Ximenes entende o potencial conflitivo da Constituição como algo a ser reconhecido e explorado de forma positiva. Neste sentido, o processo de elaboração do texto, mesmo que não revolucionário, culminou em uma redação atenta às demandas populares reformistas (XIMENES, 2014, p. 47-49).

Bonavides define a Constituição de 1988 como a Constituição do Estado Social, qualificando-se o Brasil, a partir desta, como um Estado que não apenas concede direitos sociais básicos, mas os garante. $\mathrm{O}$ autor elege como centro deste Estado Social o princípio da igualdade, entendendo que este configura um eixo em torno do qual gravita toda a estrutura pertinente ao Estado Democrático de Direito. Tal "medula axiológica" torna-se critério imperativo na interpretação do texto constitucional em matéria de direitos sociais, na medida em que possuem aplicabilidade imediata. Referido modelo de entendimento dos direitos sociais qualifica-se como de natureza assistencialista, a partir do qual citados direitos podem se traduzir numa estrutura que engloba a satisfação de necessidades básicas e que habilita as pessoas a ganhar capacidades por meio de provisão, assistência e cuidado (BARBOSA-FOHRMANN, 2012, p. 157). Por este motivo, o Estado Social inaugurado a partir da carta de 1988 é o estado produtor da igualdade fática (BONAVIDES, 2004, p. 370-378).




Na Constituição Federal de 1988, a educação é reconhecida constitucionalmente como um direito social ${ }^{3}$, qualificando-se o fornecimento dos meios de acesso a este como de competência comum da União, dos Estados, do Distrito Federal e dos Municípios. Há, no título da "Ordem Social", um detalhamento maior deste direito, ao qual é reservado um capítulo à parte ${ }^{4}$, de sorte que esta temática constitui-se como a de mais extensa regulamentação no âmbito da ordem social (SARLET, 2006, p. 350).

Em seu art. 205, a Constituição de 1988 qualifica expressamente a educação como direito de todos e dever do Estado e da família, a ser "promovida e incentivada com a colaboração da sociedade, visando ao pleno desenvolvimento da pessoa, seu preparo para o exercício da cidadania e sua qualificação para o trabalho".

Silva entende que esta norma comanda, em primeiro lugar, a organização do aparelhamento do Estado para o fornecimento, a todos, dos serviços educacionais segundo os princípios constantes na Constituição, devendo, ainda, ampliar cada vez mais as possibilidades de que todos exerçam igualmente o direito à educação; em segundo lugar, os ditames constitucionais asseguram que todas as normas da Constituição sobre educação e ensino devem ter por matriz interpretativa esta disposição, visando à sua plena e efetiva concretização nos moldes constitucionais (SILVA, 2005, p. 312-313). Neste sentido, a Constituição de 1988 eleva a educação à categoria de serviço essencial de incumbência do Poder Público, não obstante o ensino possa ser oferecido também pela iniciativa privada, que o albergará apenas de forma secundária e condicionada (SILVA, 2005, p. 838).

Apesar de definida como um direito de todos e dever do Estado e da família, notese uma diferenciação no tratamento desta prerrogativa para os titulares idosos. Vejase que - conforme o Capítulo VII (Da Família, da Criança, do Adolescente, do Jovem e do Idoso) do Título VIII (Da Ordem Social) da Constituição Federal de 1988 e conquanto conste no art. 227 que é dever da família, da sociedade e do Estado assegurar à criança, ao adolescente e ao jovem, com absoluta prioridade -, o direito à

${ }^{3}$ Art. 6º , caput, da Constituição de 1988.

${ }^{4}$ A este teor, Oliveira entende que: "A declaração do Direito à Educação é particularmente detalhada na Constituição Federal (CF) da República Federativa do Brasil, de 1988, representando um salto de qualidade com relação à legislação anterior, com maior precisão da redação e detalhamento, introduzindo-se, até mesmo, os instrumentos jurídicos para a sua garantia" (OLIVEIRA, 1999, p. 61). Duarte, analisando o modo como o direito fundamental à educação está caracterizado nos termos da constituição, elenca os seguintes fatores: a) ocupa posição de destaque no ordenamento jurídico, servindo mesmo como razão de ser de toda a ordem jurídica, juntamente com os demais direitos fundamentais; b) tem aplicabilidade imediata, embora sua realização integral só possa se dar de forma progressiva; c) não pode ser suprimida do ordenamento jurídico por meio de emenda constitucional; d) pertence a todos, mas deve priorizar categorias de pessoas que se encontram numa mesma posição de carência ou vulnerabilidade; e) tem como sujeito passivo o Estado; f) realiza-se por meio de políticas públicas ou programas de ação governamental; g) vincula a todos os poderes públicos (Executivo, Legislativo e Judiciário), que devem adotar medidas - legislativas, técnicas e financeiras - até o máximo dos recursos disponíveis, para a satisfação daquilo que foi eleito como prioritário (núcleo mínimo obrigatório), reconhecendo o direito à educação como um verdadeiro direito (DUARTE, 2007, p. 710-711). 
educação institui, sob a égide do art. 230, que referidos atores responsáveis (família, sociedade e Estado) têm, quando se trata de pessoas idosas, incumbência outra: $o$ dever de amparo. Referido dever conecta-se, segundo este preceptivo, à sua participação na comunidade, à defesa de sua dignidade e bem-estar e à garantia do direito à vida.

Há, pois, uma diferenciação entre a conduta a ser adotada pelo Estado, pela família e pela sociedade quando se trata do resguardo de prerrogativas de, em primeiro lugar, crianças, jovens e adolescentes e, em segundo lugar, pessoas idosas. A exemplo de Silva, os direitos dos idosos associam-se essencialmente ao direito previdenciário e assistencial, não chegando a alcançar, em sua acepção mais ampla, o gozo de todos os direitos sociais:

\begin{abstract}
Não foram incluídos no art. $6^{\circ}$ como espécie de direito social, mas, por certo, tem essa natureza. Uma dimensão integra o direito previdenciário (art. 201, I) e se realiza basicamente pela aposentadoria e o direito assistenciário (art. 203, I), como forma protetiva da velhice, incluindo a garantia de pagamento de um salário-mínimo mensal, quando ele não possuir meios de prover à própria subsistência, conforme, dispuser a lei. Mas o amparo à velhice vai um pouco mais longe, daí o texto do art. 230, segundo o qual a família, a sociedade e o Estado têm o dever de amparar as pessoas idosas, assegurando sua participação na comunidade, defendendo sua dignidade e bem-estar e garantindo-lhes o direito à vida, bem como a gratuidade dos transportes coletivos urbanos e, tanto quanto possível a convivência em seu lar (SILVA, 2005, p. 321).
\end{abstract}

Percebe-se, assim, a divergência discursiva no texto constitucional no que diz respeito aos direitos das pessoas idosas em face dos direitos das demais pessoas de outros espectros etários. Reforça-se, pela redação consagrada, a intelecção de que a família, a sociedade e o Estado têm a obrigação de assegurar, para as crianças, jovens e adolescentes, a efetivação de direitos - entre eles, o direito à educação -, enquanto, no caso de pessoas idosas, seu posicionamento é diverso, consistindo, sobretudo, no dever de amparo. Referida tônica altera-se, contudo, a partir dos debates que se seguiram nas últimas décadas, ao se reconhecer às pessoas idosas o status de sujeitos de direitos. Em virtude disso, devem lhes ser assegurados todos os direitos sociais, entre os quais o direito à educação, em igualdade de condições com os demais.

\title{
2. Política Nacional do Idoso de 1994: a noção de "Universidade aberta para a terceira idade"
}

A despeito de se reconhecerem na Constituição Federal de 1988 os direitos das pessoas idosas ao amparo provido pelo Estado, pela família e pela sociedade, referidas 
previsões demandam atividade legiferante em virtude de seu cunho programático ${ }^{5}$ (SARLET, 2006). Em virtude disto, em 1994, foi promulgada a Política Nacional do Idoso, cujo objetivo consiste na asseguração dos direitos sociais do idoso, criando condições para promover sua autonomia, integração e participação efetiva na sociedade ${ }^{6}$.

Conforme apontado por Sousa, a Política Nacional do Idoso "veio consolidar os direitos dos idosos já assegurados na Constituição Federal, apresentando formas de concretização de instrumento legal capaz de coibir a violação desses direitos e promover a proteção integral do idoso", de maneira a tornar-se uma "norma orientadora da atuação governamental", ao consolidar "as novas exigências da sociedade brasileira para o atendimento da população idosa" (SOUSA, 2004, p. 124). Referida política conta com 22 artigos, constando a referência à educação no Capítulo II (Dos Princípios e das Diretrizes), nestes termos:

Art. 10. Na implementação da Política Nacional do Idoso, são competências dos órgãos e entidades públicos: III - na área de educação: a) adequar currículos, metodologias e material didático aos programas educacionais destinados ao idoso; b) inserir nos currículos mínimos, nos diversos níveis do ensino formal, conteúdos voltados para o processo de envelhecimento, de forma a eliminar preconceitos e a produzir conhecimentos sobre o assunto; c) incluir a gerontologia e a geriatria como disciplinas curriculares nos cursos superiores; d) desenvolver programas educativos, especialmente nos meios de comunicação, a fim de informar a população sobre o processo de envelhecimento; e) desenvolver programas que adotem modalidades de ensino à distância, adequados às condições do idoso; f) apoiar a criação de universidade aberta para a terceira idade, como meio de universalizar o acesso às diferentes formas do saber.

Percebe-se, neste diploma, a primeira menção legislativa ao conceito de "Universidade aberta para a terceira idade", inserto no art. 10, inc. III, alínea " $\mathrm{f}$ ", como "meio de universalizar o acesso às diferentes formas do saber".

Historicamente, as primeiras universidades abertas à terceira idade foram estruturadas na França, em 1973, por meio das proposições do Professor Pierre Vellas, na Universidade de Toulouse (CACHIONI et al., 2016). A proposta inicial deste modelo educacional consubstancia-se na ocupação do tempo livre das pessoas idosas, com o

\footnotetext{
${ }^{5}$ Concordando com Bonavides, destaque-se que a programaticidade não significa ausência de eficácia: “(...) a programaticidade das Constituições será contudo um mal se não servir também ao Direito, se não for para o Poder um instrumento de racionalização e eficácia governativa, se não vier embebida de juridicidade, se não representar aquele espaço onde o espírito da Constituição elege o seu domicílio e se aloja, mas, ao contrário, venha a transformar-se nos Estados de constitucionalismo débil e apagada tradição jurídica em cômodo asilo das mais rudes transgressões constitucionais" (BONAVIDES, 2004, p. 251).

${ }^{6}$ Art. $1^{\text {o }}$ da Lei № 8.842, de 4 de janeiro de 1994.
} 
objetivo de promover o convívio social e incrementar as relações entre os idosos. Com o passar do tempo, houve a ampliação dos fins visados para abranger a melhoria da saúde mental do idoso, bem como o fomento constante de sua emancipação e de sua participação cidadã, sempre considerando suas peculiaridades (SOUSA et al., 2013).

Em território nacional, este modelo educacional foi implementado, pela primeira vez, há 22 anos, junto à Pontifícia Universidade Católica de Campinas, em 1990, que estabeleceu uma Universidade Aberta da Terceira Idade (SOUSA et al, 2013).

Atualmente, existem cerca de 200 programas desse tipo em instituições de ensino superior, a maioria destes caracterizados por projetos de extensão universitários, compondo, destarte, a educação não-formal (CACHIONI et al., 2016, p. 64). São as Universidades Abertas que despertam o debate, no âmbito dos cursos superiores, sobre da adaptação de metodologias para a educação de idosos e o acolhimento do envelhecimento como uma fase a ser considerada no processo educativo e de formação da personalidade.

\section{Estatuto do Idoso de 2003: a educação como um direito do idoso}

Apesar de contar com mais de 20 anos de existência, a Política Nacional do Idoso não encontrou efetividade prática, na medida em que não fixou uma estrita atribuição de competências às entidades responsáveis de forma que se pode afirmar que este diploma "lança a semente para a criação do Sistema Jurídico de Garantias, que ocorrerá com o Estatuto do Idoso" (ALCÂNTARA, 2016, p. 363).

Assim, considerando que "direitos apenas formalmente inseridos na lei não conferem aos idosos a dignidade, o respeito, e a integração no novo modelo da sociedade atual e nem mesmo na futura" (SOUSA, 2004, p. 9), iniciam-se, em 1997, os debates para a promulgação de uma nova legislação, que pudesse suprir as falhas de efetivação da Política Nacional do Idoso (ALCÂNTARA, 2016). Constituiu-se, em 2001, a Comissão Especial da Câmara Federal para tratar do Estatuto, com a promoção de seminários nacionais e regionais tendentes a promover debates prévios à aprovação do texto. Em virtude disto, aprova-se, em outubro de 2003, o Estatuto do Idoso, com vigência fixada a partir de $1^{\mathrm{o}}$ de fevereiro de $2004^{7}$.

Em seu art. $2^{\circ}$, explicita-se diretamente a titularidade do idoso relativa a todos os direitos fundamentais inerentes à pessoa humana e lhe são asseguradas todas as oportunidades e meio para a preservação de sua saúde física e mental e seu aperfeiçoamento moral, intelectual, espiritual e social, em condições de liberdade e dignidade. Digna de nota é a diferenciação entre a redação do art. $3^{\text {o }}$ deste diploma, que traça os deveres da família, da comunidade, da sociedade e do poder público e os direitos pertinentes à pessoa idosa, e o art. 230 da Constituição Federal de 1988, que fixava, principalmente, o dever de amparo a ser prestado pela família, pelo Estado e pela sociedade e a asseguração do direito à vida .

7 Art. 118 da Lei №. 10.741, de $1^{\text {o }}$ de outubro de 2003.

${ }^{8}$ Art. $3^{\circ}$ da Lei № 10.741 , de $1^{\circ}$ de outubro de 2003: É obrigação da família, da comunidade, da sociedade e do Poder Público assegurar ao idoso, com absoluta prioridade, a efetivação do direito à vida, à saúde,

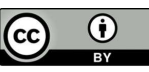


O Estatuto do Idoso, composto de 118 artigos, organizados em sete títulos, dispõe especificamente sobre a educação em seu Capítulo V, juntamente com as referências às matérias de cultura, esporte e lazer. Note-se que este texto traz a primeira referência da educação como um direito do idoso e titularizado por ele. Ademais, esta lei trata da instituição explícita e direta do dever de incumbência da família, da comunidade, da sociedade e do Poder Público de assegurar com absoluta prioridade a efetivação do direito à educação. Com este teor, dispõe a redação original do Estatuto que o "idoso tem direito à educação, cultura, esporte, lazer, diversões, espetáculos, produtos e serviços que respeitem sua peculiar condição de idade" 9 .

Fixa-se, ademais, no que diz respeito à temática de gozo do direito à educação por pessoas idosas, que o Poder Público criará oportunidades de acesso à educação, promovendo adequação de currículos, metodologias e materiais didáticos destinados aos idosos ${ }^{10}$. Neste ponto, cumpre destacar que, de acordo com Cachioni, a discussão a respeito desta temática vem ocorrendo de maneira incipiente e isolada. É preciso mais: conhecer e respeitar a história de vida destas pessoas, de forma que, enquanto educandos, não podem ser meros recipientes de conhecimento, mas devem ser percebidos como participantes ativos do saber (CACHIONI et al., 2016).

Por fim, previa-se, em redação original do art. 25 deste Estatuto, o apoio, por parte do Estado, à criação de universidade aberta para as pessoas idosas e o incentivo à publicação de livros e periódicos, de conteúdo e padrão editorial adequados ao idoso, com leitura facilitada e adaptada à natural redução da capacidade visual. Referida previsão passou, a partir da Lei №. 13.535, de 2017, para o parágrafo único deste dispositivo, sendo a nova redação do caput destinada ao acolhimento da educação de pessoas idosas na perspectiva da educação ao longo da vida.

\section{EDUCAÇÃO AO LONGO DA VIDA: ESCLARECIMENTOS CONCEITUAIS}

A expressão "Educação ao Longo da Vida" (ELV) passou a ser mundialmente utilizada a partir dos trabalhos efetivados na Comissão Internacional para $\mathrm{O}$ Desenvolvimento da Educação, que foi criada pela UNESCO e presidida por Edgar Faure. Com o passar das décadas, a expressão sofre mutações semânticas normativas e executivas, que impactaram profundamente a estruturação dos serviços educacionais voltados para a execução desta perspectiva educacional.

Nesta seção, desvelam-se as acepções associadas à ELV, buscando inteligir, em seguida, se referido conceito dá guarida à educação formal e não-formal e que tipo de perspectiva de "Educação ao Longo da Vida" pode ser defendida com vistas à

à alimentação, à educação, à cultura, ao esporte, ao lazer, ao trabalho, à cidadania, à liberdade, à dignidade, ao respeito e à convivência familiar e comunitária.

${ }^{9}$ Art. 20 da Lei №. 10.741, de $1^{\circ}$ de outubro de 2003.

${ }^{10}$ Art. 21 da Lei №. 10.741, de $1^{\text {o }}$ de outubro de 2003. 
manutenção dos princípios de preparo para a participação democrática e emancipação cidadã do educando.

\section{Educação ao longo da vida, educação permanente e aprendizagem ao longo da vida: conceitos sinônimos?}

Apesar de incluída apenas recentemente nas normas nacionais, a expressão "educação ao longo da vida" foi utilizada, pela primeira vez, na Inglaterra, em 1919, em documento intitulado Lifelong Education, Education for Life, no qual se debatia a formação vocacional dos operários. Sua tradução para o francês concretizou-se por meio do conceito de Éducation Permanente, consagrada esta a partir dos estudos de Edgar Faure, especialmente com o relatório da UNESCO de 1972, intitulado "Aprender a Ser: a educação do futuro" (GADOTTI, 2016).

Nesta investigação, admite-se que a ideia de "Educação Permanente" reportava-se inicialmente à educação de adultos, realizada comumente em cursos noturnos, sendo, em seguida, associada à educação profissional contínua, para, então, referir-se, sobretudo, ao processo educativo que considera os múltiplos aspectos da personalidade do educando, como os intelectuais, afetivos, estéticos, sociais e políticos, em uma visão integrada da ação educativa. Portanto, a "educação permanente" tornase, na década de 1970, a expressão de um relacionamento envolvente entre todas as formas, expressões e momentos do ato educativo (FAURE, 1974, p. 219-220). Neste contexto, Gadotti considera que "a matriz fundadora da Educação ao Longo da Vida é a Educação Permanente. Há total coerência entre essas duas expressões. Uma pode ser substituída pela outra sem nenhuma perda de significado" (GADOTTI, 2016, p. 52). Neste sentido, fundamenta-se uma noção processual de educação, cuja caracterização não se mostra exclusivamente pertinente a uma fase específica da vida do educando, mas também concerne todo o decurso de sua vida:

A partir de agora, a educação não se define mais em relação a um conteúdo determinado que se trata de assimilar, mas concebe-se, na verdade, como um processo de ser que, através da diversidade de suas experiências, aprende a exprimir-se, a comunicar, a interrogar o mundo e a tornar-se sempre mais ele próprio. A idéia de que o homem é um ser inacabado e não pode realizar-se senão ao preço de uma aprendizagem constante, tem sólidos fundamentos não só na economia e na sociologia, mas também na evidência trazida pela investigação psicológica. Sendo assim, a educação tem lugar em todas as idades da vida e na multiplicidade das situações e das circunstâncias da existência. Retoma a verdadeira natureza que é ser global e permanente, e ultrapasse os limites das instituições, dos programas e dos métodos que lhe impuseram ao longo dos séculos (FAURE, 1974, p. 225). 
Na década de 1990, produz-se um novo relatório no âmbito da UNESCO, intitulado "Educação, um tesouro a descobrir", que propõe uma atualização da noção de "Educação ao Longo da Vida", fundamentada em quatro pilares: aprender a aprender, aprender a conviver, aprender a fazer e aprender a ser (DELORS, 2003). A partir de tais vigas, o conceito de "Educação ao Longo da Vida" leva à eliminação da distinção tradicional entre educação formal inicial e educação permanente, convergindo em direção à noção de "sociedade educativa", no seio da qual tudo pode dar base a oportunidades de aprendizagem e de desenvolvimento de talentos (DELORS, 2003, p. 32).

Para Gadotti, este relatório deixa de enfocar a educação, desviando as intenções originais concernentes à "Educação Permanente" para a ideia de aprendizagem, omitindo, ademais, uma expressa referência ao conceito de permanência do acesso ao ensino em todas as etapas da vida (GADOTTI, 2016). Consequentemente, a reformulação proposta nas últimas décadas de ELV reproduziria um conceito de "Educação Permanente" desligado de sua proposição original, conexa à participação e à democracia, para referenciar-se em uma noção tecnicista e instrumental de educação como formação para o mercado (GADOTTI, 2016; LIMA, 2010). Surgiria, neste sentido, uma nova expressão, que, apesar de comumente utilizada como sinônimo das anteriores, encerraria um significado diverso: a noção de "Aprendizagem ao Longo da Vida".

Considerando referido enfoque na aprendizagem, reafirmou-se, em 2009, no relatório-síntese da VI Conferência Internacional de Educação de Adultos (CONFINTEA), denominado "Marco de Ação de Belém", que:

O papel da aprendizagem ao longo da vida é fundamental para resolver questões globais e desafios educacionais. Aprendizagem ao longo da vida, "do berço ao túmulo", é uma filosofia, um marco conceitual e um princípio organizador de todas as formas de educação, baseada em valores inclusivos, emancipatórios, humanistas e democráticos, sendo abrangente e parte integrante da visão de uma sociedade do conhecimento. (UNESCO, 2009, p. 06)

Portanto, apesar de possuírem a mesma matriz, as ideias de "Educação ao Longo da Vida", "Educação Permanente" e "Aprendizado ao Longo da Vida" distanciam-se em essência, se se considerarem os propósitos fixados nos marcos referenciais internacionais redigidos sobre a matéria ${ }^{11}$.

\footnotetext{
${ }^{11}$ Com este teor, afirma Gadotti: “Quando eu estava escrevendo minha tese de doutorado, nos anos 1970, não havia distinção entre 'Educação Permanente', 'Educação ao Longo da Vida' e 'Aprendizagem ao Longo da Vida', que traduziam a expressão inglesa Lifelong Education e Lifelong Learning. Essas expressões traduziam as mesmas intenções, os mesmos pressupostos. O que aconteceu nas décadas seguintes foi um completo distanciamento das raízes humanistas iniciais." (2016, p. 57).
} 
Para além de conceituações divergentes, essas siglas representam ainda um emprego desvirtuado de seu sentido teórico original, fazendo as vezes de bandeiras simbólicas da noção de educação como salvação, equivalente a um "medicamento administrado para tratar dos males de que tantos pacientes sofrem" (LIMA, 2010, p. 11). Referidos males consistem na ausência de preparação para o emprego e para a aplicação técnica de conhecimentos, persistentes, sobretudo, na realidade de indivíduos de determinados estratos sociais, os quais não são público-alvo de referidas "curas educacionais". Estas destinam-se a sanar um mal de insuficiência do indivíduo por meio da aquisição de conhecimentos que o adequam à competitividade do mundo moderno ${ }^{12}$. Pode-se inferir, portanto, que há dois sentidos de "Educação ao Longo da Vida": um conexo à intenção inicial consagrada na noção de "Educação Permanente", voltada para a participação democrática e para a emancipação cidadã do indivíduo; e outro mais afeto ao conceito de "Aprendizagem ao Longo da Vida", a partir do qual se sobressaem as noções de formação profissional e técnica, em um âmbito educacional formal e controlado ${ }^{13}$.

Considerando referida discussão, imprescindível compreender em que sentido de "Educação ao Longo da Vida" pauta-se a noção hodiernamente consagrada no Estatuto do Idoso, a fim de que possam se estruturar políticas públicas consoante com a noção processual de educação para a emancipação e para participação cidadã. Diante disso, surgem dois questionamentos: Considera-se, na expressão utilizada no Estatuto do Idoso, uma perspectiva de educação formal ou não-formal? Ainda, qual a perspectiva de "Educação ao Longo da Vida" é capaz de atender à percepção da educação como um processo infindável e permanente, consagrado à emancipação cidadã?

\section{Educação ao longo da vida: formal ou não-formal?}

Considerando a visão processual da educação, que se perpetua ao longo de toda a vida de um cidadão, é preciso compreender quais os formatos educacionais concernentes às políticas públicas derivadas do direito à educação. Afinal, fixaria o direito à educação apenas o direito à educação formal ou estaria neste albergado o ensino não-formal?

\footnotetext{
12 Para Lima, as primeiras discussões acerca de EPE fundamentavam-se na excedência de mão-de-obra e na noção de educação para a compreensão humana. Neste sentido: "não por acaso, os conceitos de educação permanente e de sociedade da aprendizagem remetiam, originalmente, para uma sociedade marcada pela existência de tempos livres, evoluindo para uma sociedade caracterizada pelo excesso de mão-de-obra. Não se tratava, portanto, da defesa de uma formação perpétua e de uma aprendizagem incessante, orientadas para a aquisição de qualificações técnicas ou de competências com vista à constituição do trabalhador flexível, como é hoje assumido pela "escola técnicoprofissional" da educação para o trabalho" (LIMA, 2010, p. 50).

13 Similarmente a esta compreensão, entende Lima: "As últimas décadas têm revelado um complexo processo de mudança, tanto conceptual quanto de orientação política, fazendo esbater a origem mais democrática e emancipatória do ideal de educação ao longo da vida e preferindo realçar as capacidades adaptativas e funcionais traduzidas pelo elogio da aprendizagem ao longo da vida" (LIMA, 2010, p. 50).
} 
Para Gadotti, a educação formal seria aquela dotada de objetivos específicos delimitados, sendo sua caracterização fixada nas instituições educacionais em sentido estrito, como escolas e universidades, dotadas de reconhecimento por órgãos oficiais e submetidas a uma fiscalização - por meio de Ministérios da Educação. Alicerça-se esta em uma diretriz educacional central - currículo - e possui estruturas e setores bem delimitados, estabelecidos hierárquica e burocraticamente. Em contraposição, a educação não-formal contaria com maior grau de difusão, não apresentando mencionadas hierarquia e burocracia, ademais de não seguir, rigidamente, um sistema de progressão e de evolução em etapas (GADOTTI, 2005).

Ao mesmo tempo que entende pela existência da distinção, Gadotti a nega, propondo que "toda educação é, de certa forma, educação formal, no sentido de ser intencional" (GADOTTI, 2005, p. 02). Destaca-se, assim, que dois fatores de distinção mais claros nesta delimitação se referem ao espaço de concretização da educação e ao tempo da aprendizagem. Neste sentido, enquanto a educação formal dar-se-á geralmente no espaço da escola, denotando sequencialidade, a educação não-formal poderá ocorrer em múltiplos ambientes além da própria instituição educacional, como em ONG's, associações de bairro e instituições comunitárias. Outrossim, enquanto há uma maior maleabilidade quanto ao tempo de aprendizagem na educação não-formal, pois atende às peculiaridades de cada indivíduo: na educação formal, há uma tendência a haver períodos delimitados para a aquisição de competências específicas, o que significa fracasso se a aquisição do conhecimento não for obtida no tempo considerado adequado.

No contexto da educação ao longo da vida, referidas noções de tempo e espaço apresentam maiores possibilidades de rearranjo, rompendo as fronteiras da estruturação estrita da educação formal. Isso não implica dizer que a educação formal deixe de figurar como um baluarte de efetivação do direito à educação na perspectiva ao longo da vida. Aqui, inclui-se na conceituação a não-formalidade, consistente na consideração de diferentes tempos e espaços de execução. Similarmente, para Gadotti:

Uma das potencialidades do princípio da "aprendizagem ao longo da vida" é que ele quebra uma visão estanque da educação, dividida por modalidades, ciclos, níveis etc. Ele articula a educação como um todo, independentemente da idade, independentemente de ser formal ou não-formal. Se a educação e a aprendizagem se estendem por toda a vida, desde o nascimento até a morte, significa que a educação e a aprendizagem não se dão somente na escola e nem no ensino formal. Elas se confundem com a própria vida, que vai muito além dos espaços formais de aprendizagem. Assim, podemos dizer que tanto a educação quanto a aprendizagem não podem ser controlados pelos sistemas formais de ensino. Este princípio nos obriga a termos uma visão mais holística da educação. (...) Por outro lado, se a educação ao longo da vida se dá em espaços formais e informais, reduzir esse conceito à educação formal seria, também, privá-lo de uma de suas grandes 
potencialidades. Por isso não devemos confundir Educação ao Longo da Vida como a Educação Formal. (GADOTTI, 2016, p. 55).

Portanto, ao se referir à perspectiva da "Educação ao Longo da Vida", o Estatuto do Idoso prevê que as atividades a serem fornecidas por meio de cursos ou programas de extensão, presenciais ou à distância, qualificam-se por serem formais e nãoformais ${ }^{14}$. Desta maneira, esclarece o Estatuto que a organização do serviço fornecido levará em conta formatações outras, não apenas aquelas fixadas no conjunto de normas oficiais, atendendo, assim, à necessidade de se considerar os diferentes contextos de vida de cada educando.

A recente modificação no diploma impõe, contudo, que estas atividades sejam fornecidas no seio das instituições de ensino superior e determina que uma entidade tipicamente associada à educação formal se responsabilize pela execução das atividades educacionais não-formais. Referida previsão consagra um contrassenso quanto ao espaço e ao ator responsável pela educação não-formal, o que implica um retrocesso a um entendimento de que a educação deve estar sob o monopólio de instituições classicamente associadas à formalidade do ensino.

\section{Por uma Educação ao Longo da Vida na Perspectiva da Educação Popular}

Considerando o analisado, a educação direcionada para idosos deve ter um enfoque que ultrapassa a aquisição de conteúdo, alinhando-se, na perspectiva da ELV, a uma noção de educação enquanto atividade em permanente processo. Neste sentido, deve-se considerá-la "como um processo de afirmação do indivíduo através da tomada de consciência para um autodeterminismo na condução de alternativas, a fim de dominar as diferentes situações em que será levado a viver" (BARCIA, 1982, p. 63).

Referida atividade inicia-se com o nascimento do indivíduo e jamais alcança seu termo, dando guarida não apenas à aprendizagem formal, mas também à informal; não apenas ao aprendizado técnico e científico, mas também à emancipação cidadã e à participação democrática. Sousa et al. entendem que estes fins educativos incluem a cidadania ativa, a realização pessoal e a integração social (SOUSA et al., 2013). Veja-se que referida percepção alinha-se ao considerado no Estatuto do Idoso, no qual estão asseguradas todas as oportunidades e meios para a preservação da saúde física e mental da pessoa idosa e seu aperfeiçoamento moral, intelectual, espiritual e social, inexistindo expressa referência ao aprimoramento laboral ou profissional ${ }^{15}$.

Tendo em vista citada delimitação de objetivos e referenciada discussão acerca das possíveis acepções advindas da interpretação do conceito de "Educação ao Longo da Vida", Gadotti entende que tais objetivos são fixados em um sentido de "Educação ao Longo da Vida" pautado pela "Educação Popular" (EPO), na medida em que, a partir da Educação Popular, a Educação ao Longo da Vida volta-se para a participação, para a cidadania e para a autonomia dos indivíduos. Neste sentido, para o autor, a Educação ao Longo da Vida, na perspectiva proposta no contexto da Educação Popular, considera as diferentes expressões da vida humana, sejam estas artísticas ou

${ }_{14}$ Art. 25, caput, do Estatuto do Idoso.

${ }^{15}$ Art. $2^{\mathrm{o}}$, caput, do Estatuto do Idoso.

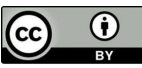

5 JOURNAL OF INSTITUTIONAL STUDIES 1 (2019)

Revista Estudos Institucionais, v. 5, n. 1, p. 147-170, jan./abr. 2019 
culturais, ligadas ou não ao desenvolvimento local e à economia solidária, à sustentabilidade socioambiental, à afirmação das identidades dos diferentes sujeitos e de seus coletivos, à inclusão digital e ao combate a qualquer tipo de preconceito (GADOTTI, 2016).

Para Pontual, afirmar a Educação ao Longo da Vida, na perspectiva da Educação Popular, significa também atribuir-lhe a missão de promover uma cidadania ativa e transformadora, e construí-la com base nas práticas da democracia participativa, objetivando um modelo de desenvolvimento promotor da justiça social, da inclusão com equidade, da sustentabilidade e da superação de todas as formas de violência e discriminação. Para o autor, referida formulação de "Educação ao Longo da Vida" direciona-se para a integração de diversas modalidades e estilos de educação e formação, institucionalizadas ou não, desenvolvidas tanto com base em organizações e movimentos sociais quanto com base em políticas públicas do Estado (PONTUAL, 2016, p. 70).

Deste modo, no âmbito da discussão conceitual entre as definições de "Aprendizagem ao Longo da Vida", "Educação ao Longo da Vida" e "Educação Permanente", a "Educação Popular" pode ser estabelecida executivamente, como substrato de orientação das políticas educacionais que consideram a continuidade da educação durante toda a vida. Neste sentido, a despeito de qual seja o termo utilizado, sempre ter-se-á em mente, na elaboração de referidas propostas educacionais voltadas para pessoas idosas, as concepções que se assentem no preparo e aperfeiçoamento para a participação democrática e para a emancipação cidadã do educando.

\section{O DIREITO À EDUCAÇÃO AO LONGO DA VIDA: ANALISANDO A NOVA REDAÇÃO DO ART. 25 DO ESTATUTO DO IDOSO}

Apresenta-se a educação como um fator essencial "para que os indivíduos tenham acesso ao conjunto de bens e serviços disponíveis na sociedade. Ela é um direito de todo ser humano como condição necessária para ele usufruir de outros direitos constituídos numa sociedade democrática" (GADOTTI, 2005, p. 01). Sua concretização influencia na formação de sujeitos de direitos participativos e emancipados, aptos a demandar diretamente os direitos fundamentais que titularizam. Pode-se entender, portanto, que a educação consiste em um direito fundamental cuja execução condiciona a qualidade da efetivação dos demais direitos fundamentais.

Nesta seção, intenta-se elucidar quais os contextos de inclusão da "Educação ao Longo da Vida" no direito interno, fixando-se as motivações legislativas que levaram à previsão desta expressão no arcabouço jurídico brasileiro. Busca-se, com isto, fixar que compreensão de "Educação ao Longo da Vida" deve ser preservada no âmbito da formulação de políticas públicas de execução desta perspectiva educacional.

\section{A inclusão da "perspectiva da educação ao longo da vida" na tramitação}




\section{legislativa}

A modificação do Estatuto do Idoso, que incluiu a perspectiva da educação ao longo da vida, apresenta, em seu processo de tramitação, eventos que fornecem pistas sobre o sentido legislativamente visado na expressão adicionada. Veja-se, a princípio, que o Projeto de Lei do Senado ${ }^{\circ} 344$, de 2012, de autoria do Senador Cristovam Buarque, previa não a alteração deste diploma, mas, sim, da LDBEN, para incluir, no art. 44, a oferta, no âmbito das instituições de ensino superior, de cursos e programas de extensão para o atendimento das pessoas idosas, por meio de atividade formais e não formais, na perspectiva da "Educação Permanente".

Em sede de justificativa, a proposição aponta o crescimento da população brasileira com mais de 60 anos de idade, sendo este contingente formado em grande parte por pessoas com escolaridade igual ou superior ao ensino fundamental. Afirmando, ademais, a multiplicação de iniciativas associadas às Universidades Abertas à Terceira Idade como indicativo de que as universidades seriam o melhor ambiente para acolher as demandas educacionais deste segmento, aponta-se que está "mais do que na hora de acolher no texto da LDB um dispositivo para articular as demandas dos idosos por educação com as atividades das instituições de educação superior" (BRASIL, 2012a).

Referida proposição, quando da análise na Comissão de Direitos Humanos e Legislação Participativa, recebeu, do relator Senador Paulo Paim, a crítica da imprecisão do texto, de maneira a deixar "margem a leituras dúbias quando de sua futura interpretação pelo Poder Judiciário" (BRASIL, 2012b), de maneira que seria preciso "estabelecer com clareza que a obrigatoriedade estabelecida no parágrafo inserido refere-se apenas à universidade pública, ficando as instituições privadas com a opção de fazê-lo" (BRASIL, 2012b). Em virtude disto, sofreu o projeto, nesta comissão, emenda com o fito de fixar aludida obrigatoriedade somente no âmbito das universidades públicas.

Em seguida, somente sob o crivo da Comissão de Educação, Cultura e Esporte a proposição de modificação legislativa voltou-se para o art. 25 do Estatuto do Idoso. Em sede de justificativa, citada alteração assentava-se sobre a necessidade de suprir uma lacuna na Lei №. 10.741 de 2004, que, apesar de garantir o direito à educação, não o fazia de modo a imprimir efetividade ao direito de acesso às pessoas idosas a programas de educação superior. Destarte, em redação final desta proposição, dispôsse que as instituições de educação superior ofertariam aos idosos, na perspectiva da "Educação Permanente", cursos e programas de extensão, presenciais ou a distância, constituídos por atividades formais e não formais. A original redação do art. 25, caput, passou, com isto, integralmente ao parágrafo único do preceptivo. Veja-se, sobre isto, que nas emendas propostas perdeu-se tanto a referência à obrigatoriedade do fornecimento de referido serviço educacional quanto a qualificação das universidades privadas como entes responsáveis.

Em tramitação na Câmara dos Deputados, o projeto seguiu sem alterações até chegar à Comissão de Direitos das Pessoas idosas, onde recebeu emenda para o acolhimento da expressão "educação ao longo da vida", em substituição à "educação permanente". Referido conceito fora acrescido sob a justificativa de que seria "mais coerente com a literatura especializada e as discussões acerca do incremento de oportunidades educacionais às pessoas idosas e aos demais cidadãos" (BRASIL, 2016). 
Mencionada emenda deixa, contudo, de conter os motivos pelos quais a Educação ao Longo da Vida seria mais adequada à estruturação da educação de idosos.

Considerando que a redação original da proposição albergava a proposta da "Educação Permanente", cumpre interpretar o texto atualmente consagrado sob a égide do art. 25 do Estatuto do Idoso a partir dos preceitos da participação democrática e a da emancipação cidadã dos educandos idosos. Veja-se que a ideia original de "Educação Permanente" compõe-se como uma crítica ao sistema educacional que segrega nas "etapas ao longo da vida os períodos de formação (correspondentes à infância e à juventude), trabalho produtivo (idade adulta) e tempo livre (velhice, tempo posterior à aposentadoria) (...), trazendo a ideia de contínua atualização de conhecimentos" (SARAIVA, 2004, p. 31). Aproxima-se, assim, de uma leitura que respeite os desígnios primeiros da educação permanente aquela que entenda a Educação ao Longo da Vida sob o viés Educação Popular (GADOTTI, 2016; PONTUAL, 2016).

\section{A modificação da LDBN para o acolhimento da educação e aprendizagem ao longo da vida}

Além das previsões constantes no Estatuto do Idoso, é preciso analisar o tratamento dispensado à educação de pessoas idosas nas demais legislações pertinentes à matéria, considerando, neste sentido, a recente alteração da LDBEN para também acolher a perspectiva da "Educação ao Longo da Vida". Primeiramente, a LDBEN não faz nenhuma referência, em sua redação, à educação de idosos, tampouco propõe o tema "envelhecimento" como componente dos currículos escolares.

Como reflexo disto, vê-se a total ausência de menção ao tema do envelhecimento e da educação de idosos nos Parâmetros Curriculares Nacionais (PCN), que, na apresentação dos temas transversais, olvida a disposição constante no Estatuto do Idoso acerca da inclusão, nos currículos mínimos dos diversos níveis de ensino formal, de conteúdos voltados ao processo de envelhecimento, ao respeito e à valorização do idoso, de forma a eliminar o preconceito e a produzir conhecimentos sobre a matéria ${ }^{16}$. Cumpre destacar também que nenhum órgão responsável por emitir pareceres, resoluções, recomendações e notas técnicas, no âmbito do Ministério da Educação entre eles, a Secretaria de Educação Continuada, Alfabetização, Diversidade e Inclusão (SECADI) -, exarou qualquer regulamentação acerca da educação de idosos (CACHIONI et al., 2016).

A despeito de não comportar nenhuma previsão acerca da educação de idosos, a LDBEN prevê, em seu art. 37, caput, a educação de jovens e adultos, destinada àqueles que não tiveram acesso ou continuidade de estudos no ensino fundamental e médio na idade própria. No $\S 1^{\circ}$ deste dispositivo, estabelece-se ainda que os sistemas de ensino devem assegurar gratuitamente aos jovens e aos adultos, que não puderam efetuar os estudos na idade regular, oportunidades educacionais apropriadas,

\footnotetext{
${ }^{16}$ Art. 22 da Lei No ${ }^{\circ} 10.741$, de $1^{\text {o }}$ de outubro de 2003.
} 
considerando as características do alunado, seus interesses, condições de vida e de trabalho, mediante cursos e exames.

Em consequência disto, a educação de idosos tem sido incluída, genericamente, na Educação de Jovens e Adultos (EJA), sem especificações referentes a este alunado. Outrossim, associa-se, nesta legislação, a educação fornecida para além do período considerado como adequado para escolarização, como estritamente voltada para suprir uma insuficiência do sistema educacional, que fracassou no fornecimento do serviço educacional na idade própria. A EJA - incluindo a educação de idosos - é legislativamente concebida, neste esteio, como uma "escolarização de segunda oportunidade", cujo efeito principal é o de remediação (LIMA, 2016, p. 17). Tem-se, assim, uma perpetuação da ideia de educação, aprendizagem e ensino como específica de determinada fase da vida e destoante da noção de educação como um processo que se realiza no delongar de toda a vida.

Em modificação ao texto da LDEBN, a Lei № 13.632, de 6 de março de 2018 inclui, no texto deste diploma normativo, a perspectiva da educação ao longo da vida para assegurar que, mesmo nos casos de escolarização na idade apropriada, haverá o fornecimento de oportunidades educacionais a todos - incluindo as pessoas idosas. Neste sentido, o art. $3^{\mathbf{0}}$ deste diploma passa a incluir, como um de seus princípios, a garantia do direito à educação e à aprendizagem ao longo da vida. Ademais, a redação do art. 37 é modificada para que a EJA seja destinada àqueles que não tiveram acesso ou continuidade de estudos nos ensinos fundamental e médio na idade própria, deixando-se claro que esta constitui instrumento para a educação e a aprendizagem ao longo da vida. Desta forma, garante-se que, mesmo quando se tenha em vista a escolarização do educando, suas peculiaridades serão consideradas no processo de aprendizagem, partindo-se de seu saber de mundo e de suas experiências individuais anteriores.

\section{EJA ou ELV? Por um entendimento do direito à educação de jovens, adultos e idosos na perspectiva da ELV sob o viés da EPO}

Como visto, a educação de idosos tem sido tratada dentro do contexto geral da EJA em virtude da ausência de menções específicas no âmbito das metodologias e de currículos acerca do ensino deste segmento. Assim, as Políticas Públicas Educacionais, fundamentadas em referidas perspectivas, findam por compreender o idoso como adulto, não se tendo em conta suas demandas específicas enquanto alunado.

De fato, o grupo de idosos está incluído genericamente em regulamentações associadas à modalidade "EJA", mencionando-se, neste sentido, o Parecer 11/2000 da Câmara de Educação Básica do Conselho Nacional de Educação, que traça as Diretrizes Curriculares Nacionais para a Educação de Jovens e Adultos. Neste, estabelece-se que "a barreira posta pela falta de alcance à leitura e à escrita prejudica sobremaneira a qualidade de vida de jovens e de adultos, estes últimos incluindo também os idosos" (CURY, 2000).

Denota-se, assim, a referência ao segmento de pessoas idosas", sem um maior detalhamento ou consideração de especificações de suas demandas educacionais. Ademais, considerando-se o sentido dos mencionados preceptivos e propondo-se a 
EJA como uma modalidade compensatória e de segunda oportunidade, cumpre-se repetir o questionamento já alinhado em Lima: quando esta "não for mais necessária num dado momento histórico (como acontece já em vários países), isso significará, então, que poderemos prescindir de políticas públicas de educação de adultos?" (LIMA, 2016, p. 18).

Do mesmo modo, a ELV é, por vezes, considerada como equivalente da EJA, entendendo-se por "Educação ao Longo da Vida" o ensino efetivado depois da idade considerada apropriada. Não obstante, a referidas expressões não são sinônimas, e uma não pode ser substituída pela outra, dado que a ELV é "mais ampla do que o universo da EJA e também da educação popular de adultos, representando uma filosofia educativa que pode conferir uma nova centralidade à EJA, dependendo, no entanto, de sua orientação político-educativa" (LIMA, 2016, p. 15). Deste modo, não se pode confundir "Educação de Jovens e Adultos" com "Educação ao Longo da Vida", uma vez que "se as duas expressões se identificassem não seria uma educação 'ao longo da vida', mas apenas ao longo da vida dos adultos. Seria ao 'longo da vida', menos a vida da criança e do adolescente" (GADOTTI, 2016, p. 50).

A despeito de não se confundirem referidas expressões, o surgimento da ELV nas agendas políticas tem suscitado o debate do esquecimento dos esforços despendidos na alfabetização e na escolarização propostas pela EJA. Gadotti aponta que a EJA "vem sendo subsumida pela Educação ao Longo da Vida", em virtude de sua ineficiência como "uma política 'compensatória', uma política desatualizada diante dos compromissos assumidos pelo Brasil", em virtude do que "seria preciso ressignificar o conceito de Educação de Jovens e Adultos (EJA) com base na visão da Educação ao Longo da Vida" (GADOTTI, 2016, p. 65). Para o autor, referida reformulação conceitual significaria uma inversão de prioridades, visto que o analfabetismo entre adultos e idosos permanece ainda como uma significativa problemática não suficientemente endereçada na agenda política educacional:

O analfabetismo continua fora da agenda política. Parece que cansamos de alfabetizar adultos. É a política da desistência. Não respeitando a biografia dos analfabetos adultos, tentamos "letrá-los" e não conseguimos. Então, coloca-se a culpa nos próprios analfabetos. Eles são inalfabetizáveis! Não podemos considerar os adultos e os idosos seres inalfabetizáveis. Não acredito na política da inalfabetizabilidade. Por causa dessa política, 13 milhões de brasileiros vão morrer sem nunca ter lido um livro. Mas não serão só eles a terem perdido a leitura dos livros. O Brasil perderá também 13 milhões de histórias que não encontraram papel, lápis e caneta para serem registradas. Isso empobrece um país. É a renúncia a um Brasil alfabetizado (GADOTTI, 2016, p. 66).

Por este motivo, antes de se falar de uma Educação ao Longo da Vida que subjugue as políticas de Educação de Jovens e Adultos ou de uma inversão de prioridades para 
o favorecimento da educação de idosos em universidades, faz-se necessário compreendê-las como derivações legislativas e executivas de uma mesma proposta conceitual. Portanto, uma proposição de ELV que promova a abertura dos ambientes universitários para a terceira idade não deve se contrapor ao ensino oferecido a idosos no âmbito da EJA, na medida em que ambos devem ter os mesmos objetivos de permanente desenvolvimento pessoal, social e político de educandos idosos.

Desta maneira, articulam-se os art. 25 do Estatuto do Idoso e art. 37 da LDBEN para que ambas as propostas educacionais sejam articuladas por uma mesma perspectiva filosófica de "Educação ao Longo da Vida" sob o viés da "Educação Popular". Por esta argumentação, as políticas educacionais em jogo nesta base conceitual promovem uma "educação transformadora, entendendo a educação como um processo de conscientização e de transformação social, num movimento permanente de superação da desumanização" (GADOTTI, 2016, p. 64).

\section{CONCLUSÃo}

Neste trabalho, percebeu-se, inicialmente, por meio do histórico traçado a partir da Constituição Federal de 1988, que o direito à educação de pessoas idosas apenas recentemente, a partir do Estatuto do Idoso de 2003, vem sendo tratado expressamente. Neste sentido, inferiu-se que o Texto Constitucional, apesar de tratar da educação como um direito de todos, dispôs especificamente sobre o dever de amparo da família, da sociedade e do Estado para com pessoas idosas, deixando de referenciar especificamente os direitos sociais pertinentes a este segmento. Além disso, a Política Nacional de Idosos de 1994, a despeito de tratar da competência de órgãos e entidades públicas no tocante à área da educação, não previu a estruturação de uma política pública educacional apta a articular os conceitos por ela instaurados, como o de Universidade Aberta à Terceira Idade.

Perscrutaram-se, em seguida, os conceitos associados à "educação ao longo da vida", intentando desvendar o significado da inclusão desta expressão no Estatuto do Idoso, a partir da Lei №. 13.535, de 2017. Foram identificados debates sobre essa concepção, nascidos da ideia de "educação permanente", que buscava, em sua formatação original, promover a participação democráticas de pessoas idosas. Demonstrou-se que, a partir das discussões e negociações internacionais ocorridas na segunda metade do século XX, a expressão passou a ser paulatinamente substituída por outras, a saber "Educação ao Longo da Vida" e "Aprendizagem ao Longo da Vida", sendo a primeira mais recorrentemente utilizada nos documentos acerca da temática. Concluiu-se pela necessidade de se fixar uma perspectiva de "Educação ao Longo da Vida" aproximada às noções de "Educação Popular", tendo em vista as preocupações esposadas por esta com a emancipação cidadã e a participação democrática dos educandos.

Ao fim, analisaram-se os processos legislativos que conduziram à inclusão da perspectiva da "Educação ao Longo da Vida" no art. 25 do Estatuto do Idoso e no art. 37 da LDBEN. Mostrou-se, inicialmente, que a redação original da proposição que alterou o Estatuto do Idoso reportava-se à ideia de "Educação Permanente", fixando, ademais, a obrigatoriedade de prestação do serviço pelas universidades tanto públicas

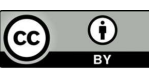


quanto privadas. Inferiu-se, por fim, que a inclusão da perspectiva da "Educação ao Longo da Vida" na LDBEN, que considera as prestações educacionais executadas na EJA, em decorrência do art. 37 da LDBEN, e nas instituições de ensino superior, em virtude do art. 25 do Estatuto do Idoso, deve comungar de uma mesma filosofia educacional, que considere as peculiaridades do educando idoso por meio de currículos e metodologias específicas, buscando-se, permanentemente, o fomento ao seu desenvolvimento pessoal, social e político.

\section{REFERÊNCIAS}

ARAÚJO, Luana Adriano. Os desafios para a efetivação do direito à educação inclusiva: igualdade, diferença e deficiência nas escolas públicas municipais de Fortaleza (CE). 2018. Dissertação de Mestrado. UFC.

ALCÂNTARA, Alexandre de Oliveira. Da Política Nacional do Idoso ao Estatuto do Idoso: a difícil construção de um sistema de garantias de direitos da pessoa idosa. Política Nacional do Idoso: velhas e novas questões. Rio de Janeiro. Ipea, 2016.

BARBOSA-FOHRMANN, Ana Paula; DE BRITO LANES, Rodrigo. O direito à educação inclusiva das crianças portadoras de deficiência. Espaço Jurídico, v. 12, n. 1, p. 155-173, 2012.

BARCIA, Mary F. Educação Permanente no Brasil. Petrópolis, Vozes, 1982.

BONAVIDES, Paulo. Curso de Direito Constitucional. 15. Ed. São Paulo: Malheiros. 2004.

BRASIL. Câmara dos Deputados. Parecer da Comissão de Defesa dos Direitos das Pessoas Idosas acerca do Projeto de Lei №. 6.350, de 2013. Relatora Deputada Leandre. 2016.

BRASIL. Senado Federal. Projeto de Lei do Senado № 344, de 2012. Autoria: Senador Cristovam Buarque. 2012a. 
BRASIL. Senado Federal. Parecer acerca do Projeto de Lei do Senado № 344/2012. Comissão de Direitos Humanos e Legislação Participativa. Relatoria: Senador Paulo Paim. 2012b.

CURY, Carlos Roberto Jamil. Parecer CNE/CEB 11/2000 que dispõe sobre as Diretrizes Curriculares para a Educação de Jovens e Adultos. Brasília, DF: MEC/CNE, 2000.

DELORS, Jacques. Educação: um tesouro a descobrir. Relatório para a Unesco da Comissão Internacional sobre Educação para o século XXI. 8. ed. São Paulo/ Brasília: Cortez/MEC, 2003.

DUARTE, Clarice Seixas. A educação como um direito fundamental de natureza social. Educação \& Sociedade, v. 28, n. 100, p. 691-713, 2007.

FAURE, Edgar. Aprender a ser. Lisboa: Bertrand, Difusão Européia do Livro, 1974.

GADOTTI, Moacir. Educação Popular e Educação ao longo da vida. In: Brasil. Ministério da Educação. Secretaria de Educação Continuada, Alfabetização, Diversidade e Inclusão. Coletânea de textos CONFINTEA Brasil+6: tema central e oficinas temáticas. Brasília: MEC, 2016.

GADOTTI, Moacir. A questão da educação formal/não-formal. Sion: Institut Internacional des Droits de 1ํㅡㄹ, Enfant, p. 1-11, 2005.

LIMA, Licínio C. A Educação faz tudo? Crítica ao pedagogismo na “sociedade da aprendizagem”. Revista Lusófona de Educação, n. 15, p. 41-54, 2010.

LIMA, Licínio C. Do aprender a ser à aquisição de competências para competir: adaptação, competitividade e performance na sociedade da aprendizagem. 2004.

LIMA, Licínio C. Aspectos Contemporâneos da Educação ao Longo da Vida. In: Brasil. Ministério da Educação. Secretaria de Educação Continuada, Alfabetização, Diversidade e Inclusão. Coletânea de textos CONFINTEA Brasil+6: tema central e oficinas temáticas. Brasília: MEC, 2016. 
MARTIN, Claudia et al. Human Rights of older people: universal and regional legal perspectives. Ius Gentium Comparative Perspectives on Law and Justice, v. 45, Springer. 2015.

CACHIONI, M. et al. Brazil. In: FINDSEN, Brian et al. (Eds). International Perspectives on Older Adult Education: Research, Policies and Practice. Suíça: Springer, 2016.

OLIVEIRA, Ivanilde Apoluceno. Texto 1 - Educação de jovens, adultos e idosos. In: BRASIL. Ministério da Educação. Secretaria de Educação à distância. Educação ao longo da vida. Ano XIX, no 11. Brasília: MEC, 2009.

OLIVEIRA, Romualdo Portela de. O Direito à Educação na Constituição Federal de 1988 e seu restabelecimento pelo sistema de Justiça. Revista Brasileira de Educação, v. 11, p. 61-74, 1999.

PONTUAL, Pedro. Educação ao Longo da Vida na perspectiva da Educação Popular e da participação social. In: Brasil. Ministério da Educação. Secretaria de Educação Continuada, Alfabetização, Diversidade e Inclusão. Coletânea de textos

CONFINTEA Brasil+6: tema central e oficinas temáticas. Brasília: MEC, 2016.

SARAIVA, Irene Skorupski. Educação de jovens e adultos: dialogando sobre aprender e ensinar. Passo Fundo: UPF. 2004.

SARLET, Ingo Wolfgang. A eficácia dos Direitos Fundamentais. 6. ed. Porto Alegre: livraria do advogado. 2006.

SILVA, José Afonso da. Curso de Direito Constitucional Positivo. 25. ed. São Paulo: Malheiros. 2005. p. 312-313.

SOUSA, Ana Maria Viola de et al. Direito dos idosos à educação: análise do filme "o estudante" sob a perspectiva pontual da Gerontagogia. In: Políticas Culturais em Revista, v. 1, n. 6, p. 137-151, 2013. 
SOUSA, Ana Maria Viola de. Tutela jurídica do idoso: a assistência e a convivência familiar. São Paulo: Alínea, 2004.

TOMASEVSKI, Katarina. Human rights obligations: making education available, accessible, acceptable and adaptable. Lund: Right to Education Primers, 2001.

UNESCO. Declaração de Hamburgo sobre a Educação de Adultos.V Conferência Internacional sobre Educação de Adultos. Hamburgo, Alemanha, julho. 1997.

UNESCO. Marco de Ação de Belém. VI Conferência Internacional de Educação de Adultos. Belém: UNESCO, 2009.

UNITED NATIONS. Political declaration and Madrid International Plan of Action on Ageing. Second World Assembly on Ageing, Madrid, Spain, 8-12 April 2002. Disnponível em: <http://www.un.org/en/events/pastevents/pdfs/Madrid_plan.pdf> Acesso em: 03 ago. 2018.

XIMENES, Salomão Barros. Direito à qualidade na educação básica: teoria e crítica. São Paulo: Quartier Latin. 2014. 